Archived version from NCDOCKS Institutional Repository http://libres.uncg.edu/ir/asu/

\title{
Appalachľan
}

B O O N E, N O R T H C A R O L I N A

\section{The Impact Of Work Organization, Job Stress, And Sleep On The Health Behaviors And Outcomes Of U.S. Long-Haul Truck Drivers}

\author{
By: Adam Hege, PhD, MPA, CHES, Michael K. Lemke, PhD, Yorghos Apostolopoulos, PhD, and
} Sevil Sönmez, PhD

\begin{abstract}
Background. Compared with other occupations, long-haul truck drivers (LHTD) engage in excessively unhealthy behaviors and experience disproportionately poor health outcomes. Health promotion efforts targeting LHTDs focus on improving individual-level behaviors; however, this occupation is replete with adverse work organization characteristics, high job stress, and compromised sleep health, which are hypothesized to cause poor health behaviors and outcomes among LHTDs. Therefore, the purpose of this study was to explore the connections between work characteristics, job stress, and sleep outcomes, and health behaviors and physical and mental health outcomes among LHTDs. Method. This was a cross-sectional study, using interviewer-administered surveys with LHTDs $(n=260)$.

Bivariate correlation analysis was used to explore the associations among work organization, job stress, sleep health, and health behaviors and outcomes. Logistic regression analyses were used to determine whether these work organization, job stress, and sleep factors predicted health behaviors and outcomes. Results. Long work hours of more than 11 hours daily (odds ratio $[O R]=2.34$ ) resulted in increased odds of high caffeine consumption. High job stress $(O R=0.48)$ and poor sleep quality $(O R=0.42)$ led to decreased odds for spending at least 1 hour daily for cooking/eating. Low sleep duration, less than 7 hours daily $(O R=2.55)$, led to increased odds of a physical health diagnosis. Both high job stress $(O R=3.58)$ and poor sleep quality $(O R=2.22)$ resulted in increased odds of a mental health diagnosis. Conclusion. Health promotion efforts targeting LHTDs need to be coupled with upstream policy, environmental, and systems-level change, especially at the governmental and trucking industry levels.
\end{abstract}

Hege, A., Lemke, M. K., Apostolopoulos, Y., \& Sönmez, S. (2019). The Impact of Work Organization, Job Stress, and Sleep on the Health Behaviors and Outcomes of U.S. Long-Haul Truck Drivers. Health Education \& Behavior, 46(4), 626-636. https://doi.org/10.1177/10901981 19826232. Publisher version of record available at: https://journals.sagepub.com/doi/full/10.1177/1090198119826232 


\title{
The Impact of Work Organization, Job Stress, and Sleep on the Health Behaviors and Outcomes of U.S. Long-Haul Truck Drivers
}

\author{
Adam Hege, PhD, MPA, CHES', Michael K. Lemke, PhD ${ }^{2,3}$, \\ Yorghos Apostolopoulos, PhD $^{2,3}$, and Sevil Sönmez, PhD $^{4}$
}

\begin{abstract}
Background. Compared with other occupations, long-haul truck drivers (LHTD) engage in excessively unhealthy behaviors and experience disproportionately poor health outcomes. Health promotion efforts targeting LHTDs focus on improving individual-level behaviors; however, this occupation is replete with adverse work organization characteristics, high job stress, and compromised sleep health, which are hypothesized to cause poor health behaviors and outcomes among LHTDs. Therefore, the purpose of this study was to explore the connections between work characteristics, job stress, and sleep outcomes, and health behaviors and physical and mental health outcomes among LHTDs. Method. This was a cross-sectional study, using interviewer-administered surveys with LHTDs $(n=260)$. Bivariate correlation analysis was used to explore the associations among work organization, job stress, sleep health, and health behaviors and outcomes. Logistic regression analyses were used to determine whether these work organization, job stress, and sleep factors predicted health behaviors and outcomes. Results. Long work hours of more than II hours daily (odds ratio $[O R]=2.34$ ) resulted in increased odds of high caffeine consumption. High job stress $(O R=0.48)$ and poor sleep quality $(O R=0.42)$ led to decreased odds for spending at least I hour daily for cooking/eating. Low sleep duration, less than 7 hours daily $(O R=2.55)$, led to increased odds of a physical health diagnosis. Both high job stress $(O R=3.58)$ and poor sleep quality $(O R=2.22)$ resulted in increased odds of a mental health diagnosis. Conclusion. Health promotion efforts targeting LHTDs need to be coupled with upstream policy, environmental, and systems-level change, especially at the governmental and trucking industry levels.
\end{abstract}

\section{Keywords}

health behavior, health disparities, job stress, long-haul truck drivers, sleep, work organization

Adverse work organization, specifically scheduling practices (e.g., long hours, shift work, etc.), and job stress (e.g., fast pace, time pressures) have been negatively associated with health behaviors and outcomes as well as health inequities across occupational sectors (Ahonen, Fujishiro, Cunningham, \& Flynn, 2018; Alterman, Luckhaupt, Dahlhamer, Ward, \& Calvert, 2013; Landsbergis et al., 2018). Concerning health behavior, epidemiologic evidence has linked the two with physical inactivity (Kouvonen et al., 2013; Oshio, Tsutsumi, \& Inoue, 2016), alcohol use (Heikkila et al., 2013; Virtanen et al., 2015), smoking (Heikkila et al., 2013), and poor eating habits (Lowden, Moreno, Holmback, \& Tucker, 2010), to name a few. Mental illness (Harvey et al., 2017), impaired sleep (Litwiller, Snyder, Taylor, \& Steele, 2017), and obesity and cardiometabolic disease (Luckhaupt, Cohen, Li, \& Calvert, 2014; Schnall, Dobson, \& Landsbergis, 2016) are frequent health complications associated with stressful work conditions. Long working hours and shift work conditions have fueled increased caffeine consumption, which has become prevalent and a factor in poorer sleep quality (Yong, Li, \& Calvert, 2017). Furthermore, sleep problems could mediate the effects of workplace stress on physical and mental health complications (Litwiller et al., 2017). Workers in the agriculture, transportation, health care, and construction industries are frequently associated with these

\footnotetext{
'Appalachian State University, Boone, NC, USA

${ }^{2}$ University of Houston-Downtown, Houston, TX, USA

${ }^{3}$ Texas A\&M University, College Station, TX, USA

${ }^{4}$ College of Business Administration, University of Central Florida,

Orlando, FL, USA

Corresponding Author:

Adam Hege, Department of Health \& Exercise Science, Appalachian State University, I 79 Leon Levine Hall, PO Box 3207I, Boone, NC 28607, USA.

Email: hegeba@appstate.edu
} 
occupational health disparities (Landsbergis, Grzywacz, \& Montagne, 2014).

The health of the nearly 2 million U.S. long-haul truck drivers (LHTDs) has been substantially affected by work organization characteristics and job stress (Apostolopoulos, Lemke, \& Sönmez, 2014). LHTDs traverse national interstates daily and are often away from home for extended time periods; while on the road, drivers encounter delivery time pressures, drive for long hours, and experience irregularity in their work schedules (Birdsey et al., 2015). The profession has been associated with poorer health behaviors (Birdsey et al., 2015), accident risks associated with inadequate sleep (Chen et al., 2015; Chen, Fang, Guo, \& Hanowski, 2016), mental illness (Apostolopoulos, Sönmez, Hege, \& Lemke, 2016), and obesity and cardiometabolic disease risk outcomes (Apostolopoulos, Lemke, et al., 2016; Hege et al., 2017). When LHTDs end their work day to rest and sleep at a truck stop, they are immersed in obesogenic environments that lack nutritious food options and physical activity opportunities (Apostolopoulos et al., 2012; Apostolopoulos, Sönmez, Shattell, Haldeman, et al., 2011). Consequently, the profession remains among the most unhealthy and unsafe occupations.

The majority of workplace health promotion efforts targeting LHTDs have continued to focus on individual-level behavior change, with little attention directed at improving adverse work conditions and reducing job stress by modifying public policy at the federal level or amending scheduling practices across the trucking industry (Hege, Perko, Apostolopoulos, Sönmez, \& Strack, 2015; Lemke \& Apostolopoulos, 2015, 2016; Ng, Yousuf, Bigelow, \& Van Eerd, 2015). It is unclear, however, how these upstream forces affect and shape health behaviors and outcomes. It is vital to have a clear understanding of them in order to inform both extant individual-level health promotion interventions as well as future policy, environmental, and systems-level changes. Therefore, the purpose of the current study was to explore the connections between LHTD work organization characteristics, job stress, and sleep health, and health behaviors and outcomes. Based on the supporting literature, we hypothesized that the combination of adverse work organizations, job stress, and poor sleep significantly shapes both health behaviors and subsequent physical and mental health outcomes.

\section{Method}

\section{Study Design and Participants}

Using a cross-sectional research design, the researchers used interviewer-administered surveys to collect data from 260 male LHTDs at a large truck stop in central North Carolina. Further details about the methods have been provided in our previous articles using these data (Apostolopoulos, Lemke, et al., 2016; Hege, Apostolopoulos, Perko, Sönmez, \&
Strack, 2016; Hege et al., 2017; Hege, Perko, Johnson, et al., 2015; Lemke, Apostolopoulos, Hege, Wideman, \& Sönmez, 2017a; Lemke, Hege, Apostolopoulos, Wideman, \& Sönmez, 2017; Lemke, Hege, Perko, Sönmez, \& Apostolopoulos, 2015). In the present study, we focused on characteristics of work organization, job stress, sleep duration and quality, health behaviors, and diagnoses that entail physical and mental health complications. The institutional review board at the University of North Carolina at Greensboro (UNCG) approved the study.

\section{Measures}

Work Scheduling Practices and Job Stress. To assess work organization characteristics, the drivers were asked about their average daily work hours and the regularity of their daily schedule. The question on work hours was formed in a categorical fashion in hourly increments; based on the U.S. Department of Transportation's (n.d.) regulations concerning driving time, we further grouped this variable as "11 hours or less" and "more than 11 hours." Response selections for daily schedules were "same every day" and "different every day." Regarding job stress, the drivers were asked how often they encountered time pressures and a fast work pace, with the responses ranging from "never" to "always." The two variables were categorized as "never or rarely" and "sometimes to always." In addition, the participants were asked to report their overall perceptions of their own stress, and the responses were grouped as "none to mild" or "moderate to chronic."

Sleep Duration and Quality. To measure sleep duration, the drivers were asked, "How many hours of sleep do you average per day?" Based on the National Sleep Foundation (n.d.) guidelines for sleep for adults, the responses were grouped as "less than seven hours" or "seven hours or more." Regarding sleep quality, the drivers were asked, "How often do you get a good night's sleep?"-with response selections ranging from "never" to "every night." We grouped the variable as "never or rarely" to represent poor sleep and "almost or every night" to represent good sleep.

Health Behaviors. Specific health behaviors included alcohol consumption on nonworkdays, caffeine consumption, smoking, daily time spent exercising, and daily time spent cooking/eating. The question on alcohol consumption was asked only about nonworkdays because very few drivers reported consuming any alcohol on workdays. This question was asked in a categorical fashion in "number of drink" increments, with the responses grouped as "none" or "one or more drinks." Caffeine consumption was asked in a continuous manner in terms of ounces and categorized as "39 oz. or less" or " $40+$ oz." These responses were grouped this way with the assumption that $40+$ oz. equaled two or more "large" coffees ( 20 oz.) per day and an extremely high caffeine 
intake. Regarding smoking, the drivers were simply asked, "How much do you smoke per day?"-with the responses leading to categorization of the drivers as "nonsmoker" if reporting not smoking and "current smoker" if reporting any level of smoking. Exercise and nutritional intake (cooking/ eating) were asked about in the format of "daily time spent," with the response choices being "no time," "a few minutes to less than 1 hour," "one to 3 hours," and "3 or more hours." With exercise, we only focused on whether the driver was active at all-that is, "no time active/sedentary" or "moderately active/active;" for nutritional intake, the responses were categorized as "few minutes to less than 1 hour" or " 1 hour or more."

Diagnoses With Health Complications. The drivers were asked about their diagnosis with a health condition, to include hypertension, cardiovascular problems, high cholesterol, diabetes, anxiety, depression, chronic fatigue syndrome, and frequent or severe headaches. These were further grouped as physical health and mental health complications. Hypertension, cardiovascular problems, high cholesterol, and diabetes were included in the "physical" health category and anxiety, depression, chronic fatigue syndrome, and frequent or severe headaches in the "mental" health category.

\section{Statistical Analyses}

Descriptive and exploratory correlation analyses were the first to be examined among the variables. Bivariate correlation analysis was used to further group the variables together to explore any predictive relationships between work organization, job stress, and sleep, and subsequently, health behaviors and physical and mental health complications were explored as outcomes. Binary logistic regression was used. In the first model, health behaviors were used as independent outcome variables, with work organization, job stress, and sleep duration and quality serving as predictors. The second model featured the same predictors, with physical health diagnosis and mental health diagnosis as independent outcome variables. All the statistical analyses were conducted using SPSS 23.0 (IBM, 2018).

\section{Results}

\section{Descriptive Statistics}

The demographic makeup of the truck driver sample has been reported in our previous published studies (Apostolopoulos, Lemke et al., 2016; Hege et al., 2016; Hege et al., 2017; Hege, Lemke, Apostolopoulos, \& Sönmez, 2018; Lemke, Apostolopoulos, Hege, Sönmez, \& Wideman, 2016). The descriptive characteristics, in relation to work organization characteristics, of the driver sample are presented in Table 1. Long work hours, with $70.3 \%$ working more than 11 hours daily, and an irregular work schedule, with $82.7 \%$ working a shifting schedule, were prevalent. The drivers reported stressful working conditions, as $68 \%$ sometimes or always had a fast work pace and $77.7 \%$ sometimes or always experienced time pressures. Furthermore, nearly two thirds $(62.5 \%)$ of the drivers reported experiencing a moderate to chronic level of stress as a result of their job. As expected, sleep was a challenge for the drivers, who reported more sleep and better sleep quality on their nonworkdays. Specifically, $46.2 \%$ reported sleeping less than 7 hours per day on workdays, compared with only $21.9 \%$ on nonworkdays. For workdays, $38.1 \%$ evaluated their sleep quality as poor, whereas only $16.7 \%$ did so for their nonworkdays. Nearly half consumed alcohol on their nonworkdays (48.6\%) and 40 or more ounces of caffeinated beverages daily (48.1\%), and were smokers (48.6\%). Approximately 40\% were considered sedentary, and three fourths (74.2\%) spent only a few minutes to 1 hour per day on cooking and eating. A prevalence of diagnosed physical health complications was noted, with hypertension and high cholesterol being the most prevalent. More than half $(51.1 \%)$ had been diagnosed with at least one physical health complication, and approximately one quarter $(23.6 \%)$ had been diagnosed with some type of mental health complication.

\section{Bivariate Correlations}

Long work hours were significantly and positively correlated with caffeine intake, suggesting that the drivers were consuming caffeine to stay alert (Table 2). Job stress variables, as expected, showed a positive correlation; in addition, each of the variables was independently correlated with a diagnosis of a mental health condition. Sleep duration and quality were found to be significantly and positively correlated as well, particularly sleep duration on work and nonworkdays and sleep quality on work and nonworkdays. The findings also revealed a positive correlation between sleep duration and a diagnosis of a physical health condition, whereas sleep quality was found to have a positive correlation with mental health. Based on these findings, fast pace of work, time pressures, and perceived job stress were grouped into one "job stress" variable. A response of "sometimes to always" and "moderate to chronic" stress for each of the three variables was considered high stress, and everything below was viewed as low to moderate. The two individual sleep duration variables were grouped into one overall sleep duration variable, with the same done for sleep quality. A sleep duration of less than 7 hours on either work or nonworkdays was considered "inadequate," and a response of "never or rarely" to the question on getting a good night's sleep on either work or nonworkdays was deemed "poor."

\section{Logistic Regression}

The logistic regression results are given in Tables 3 and 4. In the first set of models, with each of the health behaviors as 
Table I. Descriptive Statistics: Work Organization, Perceived Job Stress, Sleep Outcomes, Health Behaviors, and Health Diagnoses.

\begin{tabular}{|c|c|c|c|}
\hline Characteristics of the long-haul truck driver sample & $M(S D)$ & Range & $n(\%)$ \\
\hline \multicolumn{4}{|l|}{ Daily work hours (average) } \\
\hline II hours or less & & & $77(29.7)$ \\
\hline More than II hours & & & $182(70.3)$ \\
\hline \multicolumn{4}{|l|}{ Daily schedule } \\
\hline Same every day & & & $45(17.3)$ \\
\hline Different every day & & & $215(82.7)$ \\
\hline \multicolumn{4}{|l|}{ Frequency of fast pace of work } \\
\hline Never or rarely & & & $83(32.0)$ \\
\hline Sometimes to always & & & $176(68.0)$ \\
\hline \multicolumn{4}{|l|}{ Frequency of time pressures } \\
\hline Never or rarely & & & $58(22.3)$ \\
\hline Sometimes to always & & & $202(77.7)$ \\
\hline \multicolumn{4}{|l|}{ Perceived stress } \\
\hline None to mild & & & $97(37.5)$ \\
\hline Moderate to chronic & & & $162(62.5)$ \\
\hline Sleep duration in hours (workdays) & $6.95(1.62)$ & $3.0-13.0$ & \\
\hline Less than 7 hours & & & $120(46.2)$ \\
\hline Seven or more hours & & & $140(53.8)$ \\
\hline Sleep duration in hours (nonworkdays) & $8.27(2.12)$ & $3.5-16.0$ & \\
\hline Less than 7 hours & & & $57(21.9)$ \\
\hline Seven or more hours & & & $203(78.1)$ \\
\hline \multicolumn{4}{|l|}{ Sleep quality (workdays) } \\
\hline Never or rarely & & & $98(38.1)$ \\
\hline Almost every night/every night & & & $159(61.9)$ \\
\hline \multicolumn{4}{|l|}{ Sleep quality (nonworkdays) } \\
\hline Never or rarely & & & $39(16.7)$ \\
\hline Almost every night/every night & & & $194(83.3)$ \\
\hline \multicolumn{4}{|l|}{ Alcohol consumption (nonworkdays) } \\
\hline None & & & $\mid 30(5 \mid .4)$ \\
\hline One + drink & & & $123(48.6)$ \\
\hline \multicolumn{4}{|l|}{ Caffeine consumption (oz./day) } \\
\hline $0-39$ & & & $135(5 \mid .9)$ \\
\hline $40+(=$ two or more "large" coffees) & & & $125(48.1)$ \\
\hline \multicolumn{4}{|l|}{ Smoking } \\
\hline Current smoker & & & $103(48.6)$ \\
\hline \multicolumn{4}{|l|}{ Daily time exercising } \\
\hline No time/sedentary & & & $102(39.4)$ \\
\hline Moderately active/active & & & $157(60.6)$ \\
\hline \multicolumn{4}{|l|}{ Daily time cooking/eating } \\
\hline Few minutes/less than I hour & & & $193(74.2)$ \\
\hline $\mathrm{I}+$ hour & & & $67(25.8)$ \\
\hline \multicolumn{4}{|l|}{ Diagnosed with } \\
\hline \multicolumn{4}{|l|}{ Physical condition } \\
\hline Hypertension & & & $85(33.6)$ \\
\hline Cardiovascular problems & & & $13(5.1)$ \\
\hline High cholesterol & & & $68(28.2)$ \\
\hline Diabetes & & & $44(17.2)$ \\
\hline \multicolumn{4}{|l|}{ Mental condition } \\
\hline Anxiety & & & $20(7.7)$ \\
\hline Depression & & & $33(12.7)$ \\
\hline Chronic fatigue syndrome & & & $27(10.4)$ \\
\hline Frequent or severe headaches & & & $24(9.2)$ \\
\hline \multicolumn{4}{|l|}{ Diagnosed with at least one } \\
\hline Physical health problem & $0.84(0.99)$ & $0-4$ & $12 \mid(5||)$. \\
\hline Mental health problem & $0.40(0.84)$ & $0-4$ & $61(23.6)$ \\
\hline
\end{tabular}



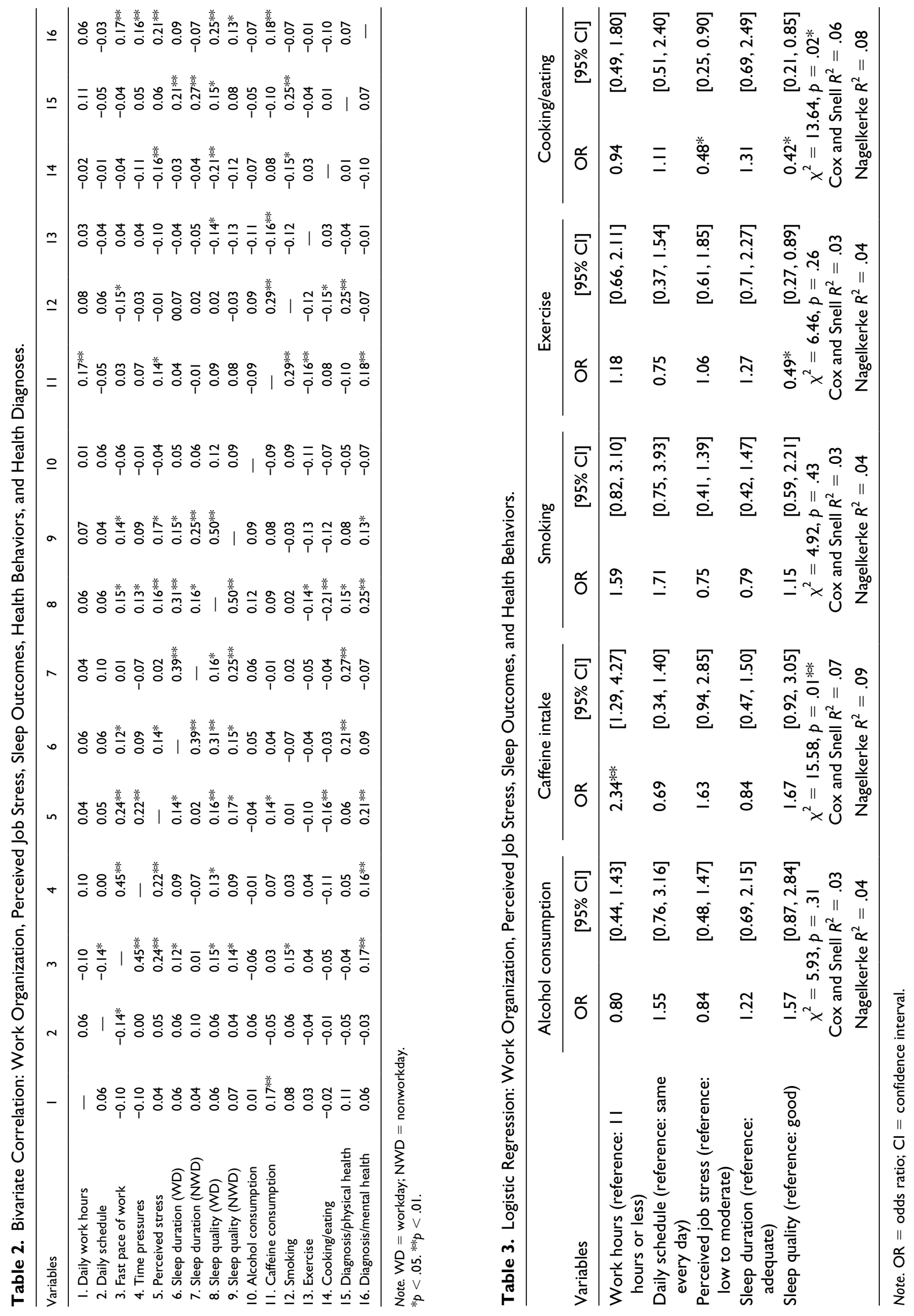
Table 4. Logistic Regression: Work Organization, Perceived Job Stress, Sleep Outcomes, and Health Diagnoses.

\begin{tabular}{|c|c|c|c|c|}
\hline \multirow[b]{2}{*}{ Variables } & \multicolumn{2}{|c|}{ Physical health } & \multicolumn{2}{|c|}{ Mental health } \\
\hline & OR & {$[95 \% \mathrm{Cl}]$} & OR & {$[95 \% \mathrm{Cl}]$} \\
\hline Work hours (reference: II hours or less) & 1.39 & {$[0.76,2.57]$} & 0.94 & {$[0.46,1.96]$} \\
\hline Daily schedule (reference: same every day) & 0.74 & {$[0.35,1.53]$} & 0.65 & {$[0.28,1.54]$} \\
\hline Perceived job stress (reference: low to moderate) & 0.71 & {$[0.40,1.28]$} & $3.58 * *$ & {$[1.76,7.26]$} \\
\hline Sleep duration (reference: adequate) & $2.55 * *$ & {$[1.39,4.69]$} & 0.82 & {$[0.40,1.69]$} \\
\hline \multirow[t]{2}{*}{ Sleep quality (reference: good) } & 1.27 & {$[0.68,2.37]$} & $2.22 *$ & {$[1.08,4.58]$} \\
\hline & \multicolumn{2}{|c|}{$\begin{array}{l}\chi^{2}=14.85, p=.01 * * \\
\text { Cox and Snell } R^{2}=.07\end{array}$} & \multicolumn{2}{|c|}{$\begin{array}{l}\chi^{2}=21.54, p=.00 * * \\
\text { Cox and Snell } R^{2}=09\end{array}$} \\
\hline
\end{tabular}

Note. $\mathrm{OR}=$ odds ratio; $\mathrm{Cl}=$ confidence interval.

$*_{p}<.05 . * * p<.01$.

outcome variables, only two of the models were statistically significant: caffeine intake $\left(\chi^{2}=15.58, p=.01\right)$ and time spent cooking and eating $\left(\chi^{2}=13.64, p=.02\right)$. Working more than 11 hours daily emerged as a statistically significant predictor of caffeine intake of 40 or more ounces a day (odds ratio $[\mathrm{OR}]=2.34$ ). There were two statistically significant predictors of spending more than 1 hour a day cooking and/or eating. Specifically, high stress $(\mathrm{OR}=0.48)$ and poor sleep quality $(\mathrm{OR}=0.42$ ) led to lower odds of spending time on cooking and/or eating. Both models for diagnosis of a physical $\left(\chi^{2}=14.85, p=.01\right)$ and mental $\left(\chi^{2}=21.54\right.$, $p=.01)$ health complication were statistically significant. For a diagnosis of a physical health complication, low sleep duration resulted in higher odds $(\mathrm{OR}=2.55)$, whereas for a diagnosis of a mental health complication, high job stress $(\mathrm{OR}=3.58)$ and poor sleep quality $(\mathrm{OR}=2.22)$ resulted in higher odds.

\section{Discussion}

Physical and mental health disparities among U.S. LHTDs have become better explicated in recent years because of increasing research attention and have caused increasing concern among drivers themselves and their families, trucking companies, public health professionals, and other stakeholders (Apostolopoulos, Lemke, Hege, et al., 2016; Apostolopoulos, Lemke, \& Sönmez, 2014; Apostolopoulos, Sönmez, Hege, \& Lemke, 2016; Garbarino et al., 2017; Korelitz et al., 1993; Krueger, Belzer, et al., 2007; Krueger, Brewster, Dick, Inderbitzen, \& Staplin, 2007; Shattell, Apostolopoulos, Collins, Sönmez, \& Fehrenbacher, 2012; Shattell, Apostolopoulos, Sönmez, \& Griffin, 2010; Sieber et al., 2014). Workplace health promotion efforts targeting LHTDs are typically low leverage and focused on inducing behavior change at the individual level, such as improving nutrition intake and increasing physical activity (Duane \& Domegan, 2010; Krueger \& Brewster, 2002; Krueger, Brewster, et al., 2007; Lemke \& Apostolopoulos, 2015; Ng et al., 2015; Olson, Anger, Elliot, Wipfli, \& Gray, 2009). In light of the current body of knowledge regarding LHTD health behaviors and the influences of these behavioral patterns on subsequent health outcomes, these health promotion programs are important. For example, LHTDs are highly sedentary and engage in very little physical activity or exercise; they typically have unhealthy diets and are likely to consume large quantities of caffeine, tobacco, and other psychostimulants to counteract work-induced fatigue (Birdsey et al., 2015; Garbarino et al., 2017; Korelitz et al., 1993; Krueger, Belzer, et al., 2007; Krueger, Brewster, et al., 2007; Layne, Rogers, \& Randolph, 2009; McCallum, Sandquist, Mitler, \& Krueger, 2003; Sieber et al., 2014; Turner \& Reed, 2011; Wawzonek, 2016; Wenger, 2008).

Unfortunately, few health promotion initiatives have targeted upper-level forces uniquely endemic to the LHTD profession that induce and constrain health-related behaviors - such as scheduling configurations, including long work hours and frequent shift work; poor sleep health; high job stress, including a fast pace of work and excessive time pressures; and workplace built environments described as healthyliving deserts (Apostolopoulos et al., 2012; Apostolopoulos, Lemke, Sönmez, \& Hege, 2016; Apostolopoulos, Peachey, \& Sönmez, 2011; Apostolopoulos, Sönmez, Shattell, Gonzales, \& Fehrenbacher, 2013; Apostolopoulos, Sönmez, Shattell, Haldeman, et al., 2011; de Pinho et al., 2006; Ebrahimi, Sadeghi, Dehghani, \& Niiat, 2015; Garbarino et al., 2017; Guglielmi, Magnavita, \& Garbarino, 2018; Jensen \& Dahl, 2009; Lemke, Meissen, \& Apostolopoulos, 2016; Shattell et al., 2010). As the current study shows, these meso- and macrolevel forces influence critical health behaviors among LHTDs. Several of these influences replicate relationships found in the existing literature. For one, fatigue has been shown to increase caffeine intake and other stimulant use among LHTDs, especially drivers who are paid by the mile versus hourly or a set salary, which has become the most common form of compensation in the trucking industry (Taylor \& Dorn, 2006; Thompson \& Stevenson, 2014). Job stress has 
also been known to influence adaptive behaviors - including dietary habits, with "comfort food" acting as a coping mechanism for LHTDs - and has been associated with poorer mental health outcomes, including anxiety, depression, and the development of mental disorders (Apostolopoulos, Peachey, et al., 2011; Apostolopoulos, Sönmez, Shattell, \& Belzer, 2011; Apostolopoulos, Sönmez, Shattell, Haldeman, et al., 2011; Guglielmi et al., 2018).

\section{Recommendations for Improving Health Behaviors and Health Outcomes}

As discussed previously, workplace health promotion efforts are important for improving healthful behaviors among LHTDs and should be encouraged and expanded, with best practices replicated throughout the trucking industry (Krueger, 2013; Krueger, Belzer, et al., 2007; Krueger \& Brewster, 2002; Krueger, Brewster, et al., 2007). However, in light of the findings of the current study, and the current body of relevant literature, these efforts are unlikely to be highly impactful without corresponding improvements being made simultaneously to the meso- and macrolevel forces that induce and constrain drivers' health behaviors (Apostolopoulos, Sönmez, Shattell, \& Belzer, 2010, 2011; Dahl et al., 2009; Krueger, Belzer, et al., 2007; Krueger, Brewster, et al., 2007; Turner \& Reed, 2011). The findings reported here indicate that work hours, sleep quality, sleep duration, and job stress may constitute key points for such upstream interventions. Furthermore, these factors have been independently associated with cardiometabolic risks (Lemke, Apostolopoulos, Hege, Wideman, \& Sönmez, 2017b; Lemke et al., 2015; Lemke et al., 2017a), which suggests that targeting these intervention points will have additional benefits beyond impacts on health behavior.

Intervention strategies to modify these forces will need to occur at levels of influence beyond the individual driver. Fortunately, these strategies can improve several of these forces simultaneously. For one, hours-of-service (HOS) rules, which are federal policies that dictate work hours and sleep duration of LHTDs, require modification. These rules currently focus on the number of hours on duty (i.e., work hours) and the number of hours of sleep (i.e., sleep duration), but they do not fully take into account what time of day sleep may be occurring and whether this time aligns with drivers' circadian rhythms (i.e., sleep quality) (Federal Motor Carrier Safety Administration, 2017; Lemke et al., 2016). However, recent changes in HOS rules have addressed circadian rhythms, such as a new requirement that "restart breaks"which allow drivers to reset the number of hours they have accumulated toward two other HOS rules (which stipulate that drivers may not drive after accruing 60 hours on duty in the past 7 days or 70 hours on duty in the past 8 days) - must include at least two nighttime (1 a.m. to 5 a.m.) periods (Dinges et al., 2015). Evaluations of this rule change have indicated that they did not affect sleep quality ratings; however, it appears that this change has had a positive impact on sleep duration (Dinges et al., 2015). Further modifying HOS rules, such as considering circadian rhythms or further restricting daily and weekly work hours, would potentially have widespread impacts for all three factors. For example, shorter work hours have been associated with reduced stress and better sleep health (Benstowe, 2008; Hege, Perko, Johnson, et al., 2015), and improving sleep health has been associated with improved stress responses and lower stress levels (Ebrahimi et al., 2015; Guglielmi et al., 2018; Krueger, Belzer, et al., 2007). Another potential avenue for interventions is at the trucking industry level, where stakeholders need to collaborate in order to reduce LHTD job stress. This can be accomplished in several ways, including by shifting away from just-in-time freight delivery systems, which have been shown to deteriorate sleep health and increase stress among drivers, and transitioning toward freight delivery systems that give LHTDs a greater degree of job control and decision latitude (Apostolopoulos, Peachey, et al., 2011; Shattell et al., 2010). Also, shippers and consignees can better accommodate drivers by avoiding overnight appointments, which contribute to the prevalence of shift work among LHTDs and also have negative impacts on sleep health, with corresponding repercussions in experiencing and managing job-related stress (Ebrahimi et al., 2015; Kanazawa, Suzuki, Onoda, \& Yokozawa, 2006). Ultimately, these and other upstream interventions will require comprehensive and collaborative efforts from the array of governmental and trucking industry stakeholders, whose economic viability is compromised by poor LHTD health.

Finally, it is imperative that the nature of the relationships between work organization characteristics, sleep, stress, and health status and health behaviors be viewed through a new paradigmatic lens - one that understands these forces to be dynamic (changing over time), complex (interrelated and interdependent), and marked by nonlinearity. For example, the increased intake of stimulants by LHTDs because of long work hours is known to negatively affect sleep health (Taylor $\&$ Dorn, 2006), which may in turn further perpetuate fatigue and the need for stimulants - representing a reinforcing feedback loop (or a vicious cycle) (Sterman, 2000). Similarly, consuming processed salt and fat-laden comfort foods as a coping mechanism for job-related stress may provide shortterm stress relief, but over time, it may induce stress and reduce the body's physiological ability to deal with stressors by generating weight gain and reducing cardiovascular functioning. Although it is beyond the scope of this article to fully delve into the dynamic complexity of LHTD health, these complex and nonlinear causal relationships warrant further exploration. Furthermore, a growing number of researchers are calling for new epistemological and methodological perspectives to untangle this dynamic complexity and to identify high-leverage intervention points among LHTDs and other vulnerable populations (Apostolopoulos, Lemke, Barry, \& Hassmiller Lich, 2018a, 2018b; Apostolopoulos, Lemke, 
Hosseinichimeh, et al., 2018; Lemke \& Apostolopoulos, 2016; Newnam, Goode, Salmon, \& Stevenson, 2017; Salmon, McClure, \& Stanton, 2012). Such new approaches may hold the potential of creating significant long-term, populationlevel improvements in LHTD health outcomes.

\section{Limitations}

There are three primary limitations of this study. First, the sample size is relatively small, with data from 260 LHTDs used in these analyses. Although a larger sample size may have increased our likelihood of finding statistically significant associations, we believe, however, that our sample size was appropriate for investigating key research questions. Second, our survey was reliant on self-reported data, which leaves open the possibility that the LHTDs may have misreported their work organization experiences, sleep quality and duration, the status of their mental and physical health, and health behaviors. However, the general congruence of these characteristics from our sample with those of other LHTD studies suggests that the data used here may be reflective of the U.S. LHTD population. Finally, as is the case with many studies using participant-recruiting strategies similar to ours, the potential for selection bias exists, and drivers may have refused to participate for any number of reasons, including being hesitant to share personal information with a government entity, namely the state university conducting this study.

\section{Conclusions}

Adverse work conditions pose significant public health challenges. The results from the present study further highlight how vulnerable populations, such as LHTDs, face unique work stressors, poor health behaviors, and subsequently worse health outcomes. It is vital that policymakers and industry officials, as well as public health practitioners, use a comprehensive, collaborative, and ecologically based perspective to intervene in both health promotion efforts and policy- and systems-level change.

\section{Acknowledgments}

Data collection for this work was done at the University of North Carolina at Greensboro (UNCG). This article is part of a commercial driver sleep study conducted with research funds awarded by the UNCG's Office of Research and Economic Development. Additional funds were provided by the UNCG's School of Health and Human Sciences, Bryan School of Business and Economics, Department of Public Health Education, and Department of Kinesiology. In addition, we would like to thank the Beaver College of Health Sciences at Appalachian State University for their funding in support of the preparation of this article. Thanks go also to Mr. Tom Liutkus, Vice President of Marketing and Public Relations for Travel Centers of America and Mr. Jerald Brisson, General Manager of the Whitsett, NC, Travel Centers of America truck stop and his staff for their instrumental support of our project and data collection efforts. We also thank the long-haul truck drivers who participated in this study.

\section{Declaration of Conflicting Interests}

The authors declared no potential conflicts of interest with respect to the research, authorship, and/or publication of this article.

\section{Funding}

The author(s) disclosed receipt of the following financial support for the research, authorship, and/or publication of this article: This article is part of a commercial driver sleep study conducted with research funds awarded by the UNCG's Office of Research and Economic Development. Additional funds were provided by the UNCG's School of Health and Human Sciences, Bryan School of Business and Economics, Department of Public Health Education, and Department of Kinesiology. Beaver College of Health Sciences at Appalachian State University provided funding in support of the preparation of this article.

\section{References}

Ahonen, E., Fujishiro, K., Cunningham, T., \& Flynn, M. (2018). Work as an inclusive part of population health inequities research and prevention. American Journal of Public Health, 108, 306-311.

Alterman, T., Luckhaupt, S., Dahlhamer, J., Ward, B., \& Calvert, G. (2013). Job insecurity, work-family imbalance, and hostile work environment: Prevalence data from the 2010 National Health Interview Survey. American Journal of Industrial Medicine, 56, 660-669.

Apostolopoulos, Y., Lemke, M., \& Sönmez, S. (2014). Risks endemic to long-haul trucking in North America: Strategies to protect and promote driver well-being. New Solutions: A Journal of Environmental and Occupational Health Policy, 24, 57-81. doi:10.2190/ns.24.1.c

Apostolopoulos, Y., Lemke, M. K., Barry, A. E., \& Hassmiller Lich, K. (2018a). Moving alcohol prevention research forward-part I: Introducing a complex systems paradigm. Addiction, 113, 353-362.

Apostolopoulos, Y., Lemke, M. K., Barry, A. E., \& Hassmiller Lich, K. (2018b). Moving alcohol prevention research forward-part II: New directions grounded in community-based system dynamics modeling. Addiction, 113, 363-371.

Apostolopoulos, Y., Lemke, M. K., Hege, A., Sönmez, S., Sang, H., Oberlin, D. J., \& Wideman, L. (2016). Work and chronic disease: Comparison of cardiometabolic risk markers between truck drivers and the general U.S. population. Journal of Occupational and Environmental Medicine, 58, 1098-1105. doi:10.1097/jom.0000000000000867

Apostolopoulos, Y., Lemke, M. K., Hosseinichimeh, N., Harvey, I. S., Hassmiller Lich, K., \& Brown, J. (2018). Embracing causal complexity in health disparities: Metabolic syndemics and structural prevention in rural minority communities. Prevention Science, 19, 1019-1029.

Apostolopoulos, Y., Lemke, M. K., Sönmez, S., \& Hege, A. (2016). The obesogenic environment of commerical trucking: A worksite environmental audit and implications for systems-based interventions. American Journal of Health Education, 47, 8593. doi:10.1080/19325037.2015.1133339 
Apostolopoulos, Y., Peachey, A. A., \& Sönmez, S. (2011). The psychosocial environment of commercial driving: Morbidities, hazards, and productivity of truck and bus drivers. In J. LanganFox \& C. Cooper (Eds.), Handbook of stress in the occupations (pp. 431-450). Northampton, England: Edward Elgar.

Apostolopoulos, Y., Shattell, M., Sönmez, S., Strack, R., Haldeman, L., \& Jones, V. (2012). Active living in the trucking sector: Environmental barriers and health promotion strategies. Journal of Physical Activity and Health, 9, 259-269.

Apostolopoulos, Y., Sönmez, S., Hege, A., \& Lemke, M. (2016). Work strain, social isolation and mental health of long-haul truckers. Occupational Therapy in Mental Health, 32, 50-69. doi:10.1080/0164212x.2015.1093995

Apostolopoulos, Y., Sönmez, S., Shattell, M., \& Belzer, M. (2011). Environmental determinants of obesity-associated morbidity risks for truckers. International Journal of Workplace Health Management, 5(2), 4-38.

Apostolopoulos, Y., Sönmez, S., Shattell, M., \& Belzer, M. H. (2010). Worksite-induced morbidities among truck drivers in the United States. American Association of Occupational Health Nurses Journal, 58, 285-296.

Apostolopoulos, Y., Sönmez, S., Shattell, M., Gonzales, C., \& Fehrenbacher, C. (2013). Health survey of U.S. long-haul truck drivers: Work environment, physical health, and healthcare access. Work, 46, 113-123.

Apostolopoulos, Y., Sönmez, S., Shattell, M., Haldeman, L., Strack, R., \& Jones, V. (2011). Barriers to truck drivers' healthy eating: Environmental influences and health promotion strategies. Journal of Workplace Behavioral Health, 26, 122-143. doi:10. 1080/15555240/2011.573754

Benstowe, S. J. (2008). Long driving hours and health of truck drivers (Unpublished master's thesis), New Jersey Institute of Technology, Newark.

Birdsey, J., Sieber, W. K., Chen, G. X., Hitchcock, E. M., Lincoln, J. E., Nakata, A., . . Sweeney, M. H. (2015). National survey of US long-haul truck driver health and injury: Health behaviors. Journal of Occupational and Environmental Medicine, 57, 210-216.

Chen, G., Fang, Y., Guo, F., \& Hanowski, R. (2016). The influence of daily sleep patterns of commercial truck drivers on driving performance. Accident Analysis \& Prevention, 91, 55-63.

Chen, G., Sieber, W., Lincoln, J., Birdsey, J., Hitchcock, E., Nakata, A., . . Sweeney, M. (2015). NIOSH national survey of long-haul truck drivers: Injury and safety. Accident Analysis \& Prevention, 85, 66-72.

Dahl, S., Kaerlev, L., Jensen, A., Tüchsen, F., Hannerz, H., Nielsen, P. S., \& Olsen, J. (2009). Hospitalization for lifestyle related diseases in long haul drivers compared with other truck drivers and the working population at large. Work, 33, 345-353. doi:10.3233/wor-2009-0882

de Pinho, R. S. N., da Silva-Junior, F. P., Bastos, J. P. C., Maia, W. S., de Mello, M. T., de Bruin, V. M. S., \& de Bruin, P. F. C. (2006). Hypersomnolence and accidents in truck drivers: A cross-sectional study. Chronobiology International, 23, 963971. doi:10.1080/07420520600920759

Dinges, D., Maislin, G., Hanowski, R., Mollicone, D., Hickman, J., Maislin, D., . . Trentalange, M. (2015). Commercial motor vehicle $(C M V)$ driver restart study (FMCSA-RRR-15-011). Retrieved from https://www.fmcsa.dot.gov/sites/fmcsa.dot .gov/files/docs/RRR-15-011-CMV\%20Driver\%20Restart\%20 Study-Final-Report-508C.pdf
Duane, S., \& Domegan, C. (2010). The Get Your Life in Gear Truck Driver social marketing intervention on the island of Ireland. Paper presented at the 9th International Congress of the International Association on Public and Nonprofit Marketing, Bucharest, Romania.

Ebrahimi, M. H., Sadeghi, M., Dehghani, M., \& Niiat, K. S. (2015). Sleep habits and road traffic accident risk for Iranian occupational drivers. International Journal of Occupational Medicine and Environmental Health, 28, 305-312. doi:10.13075/ ijomeh.1896.00360

Federal Motor Carrier Safety Administration. (2017). Summary of hours-of-service regulations. Retrieved from https://www .fmcsa.dot.gov/regulations/hours-service/summary-hours -service-regulations

Garbarino, S., Magnavita, N., Guglielmi, O., Maestri, M., Dini, G., Bersi, F. M., . . .Durando, P. (2017). Insomnia is associated with road accidents. Further evidence from a study on truck drivers. PLoS One, 12, e0187256.

Guglielmi, O., Magnavita, N., \& Garbarino, S. (2018). Sleep quality, obstructive sleep apnea, and psychological distress in truck drivers: A cross-sectional study. Social Psychiatry and Psychiatric Epidemiology, 53, 531-536.

Harvey, S., Modini, M., Joyce, S., Milligan-Saville, J., Tan, L., Mykletun, A., . . . Mitchell, P. (2017). Can work make you mentally ill? A systematic meta-review of work-related risk factors for common mental health problems. Occupational and Environmental Medicine, 74, 301-310.

Hege, A., Apostolopoulos, Y., Perko, M., Sönmez, S., \& Strack, R. (2016). The work organization of long-haul truck drivers and the association with body mass index. Journal of Occupational and Environmental Medicine, 58, 712-717.

Hege, A., Lemke, M., Apostolopoulos, Y., Perko, M., Sönmez, S., \& Strack, R. (2017). US long-haul truck driver work organization and the association with cardiometabolic disease risk. Archives of Environmental \& Occupational Health, 72, 303-310.

Hege, A., Lemke, M., Apostolopoulos, Y., \& Sönmez, S. (2018). Occupational health disparities among US long-haul truck drivers: The influence of work organization and sleep on cardiovascular and metabolic disease. PLoS One, 13, e0207322.

Hege, A., Perko, M., Apostolopoulos, Y., Sönmez, S., \& Strack, R. (2015). US long-haul truck driver demands integrated approach. International Journal of Workplace Health Management, 9, 378-397.

Hege, A., Perko, M., Johnson, A., Yu, C. H., Sönmez, S., \& Apostolopoulos, Y. (2015). Surveying the impact of work hours and schedules on commercial motor vehicle driver sleep. Safety and Health at Work, 6, 104-113. doi:10.1016/j. shaw.2015.02.001

Heikkila, K., Fransson, E., Nyberg, S., Zins, M., Westerlund, H., Westerholm, P., . . Kivimaki, M. (2013). Job strain and health-related lifestyle: Findings from an individual-participant meta-analysis of 118000 working adults. American Journal of Public Health, 103, 2090-2097.

IBM. (2018). SPSS statistics V. 23.0 documentation. Retrieved from https://www.ibm.com/support/knowledgecenter/en /SSLVMB_23.0.0/spss/product_landing.html

Jensen, A., \& Dahl, S. (2009). Truck drivers hours-of-service regulations and occupational health. Work, 33, 363-368. doi:10.3233/wor-2009-0884

Kanazawa, H., Suzuki, M., Onoda, T., \& Yokozawa, N. (2006). Excess workload and sleep-related symptoms among commercial 
long-haul truck drivers. Sleep and Biological Rhythms, 4, 121128. doi:10.1111/j.1479-8425.2006.00218.x

Korelitz, J. J., Fernandez, A. A., Uyeda, V. J., Spivey, G. H., Browdy, B. L., \& Schmidt, R. T. (1993). Health habits and risk factors among truck drivers visiting a health booth during a trucker trade show. American Journal of Health Promotion, 8 , 117-123. doi:10.4278/0890-1171-8.2.117

Kouvonen, A., Vahtera, J., Oksanen, T., Pentti, J., Vaananen, A., Heponiemi, T., . . Kivimaki, M. (2013). Chronic workplace stress and insufficient physical activity: A cohort study. Occupational and Environmental Medicine, 70, 3-8.

Krueger, G. P. (2013). Health and wellness for commercial truck, bus and motor coach drivers: Wellness report. Park Ridge, IL: American Society of Safety Engineers.

Krueger, G. P., Belzer, M. H., Alvarez, A., Knipling, R. R., Husting, E. L., Brewster, R. M., \& Siebert, J. (2007). Health and wellness of commercial drivers. In A. Petty (Ed.), The domain of truck and bus safety research (Vol. E-C117, pp. 58-91). Washington, DC: Transportation Research Board.

Krueger, G. P., \& Brewster, R. M. (2002). Gettin' in gear: Wellness, health, and fitness program for commercial drivers: Instructors manual. Alexandria, VA: American Transportation Research Institute and Federal Motor Carrier Safety Administration.

Krueger, G. P., Brewster, R. M., Dick, V. R., Inderbitzen, R. E., \& Staplin, L. (2007). Health and wellness programs for commercial drivers. Washington, DC: Transportation Research Board. Retrieved from https://www.nap.edu/catalog/23161/health -and-wellness-programs-for-commercial-drivers

Landsbergis, P., Choi, B., Dobson, M., Sembajwe, G., Slatin, C., Delp, L., . . Baron, S. (2018). The key role of work in population health inequities. American Journal of Public Health, 108, 296-297.

Landsbergis, P., Grzywacz, J., \& Montagne, A. (2014). Work organization, job insecurity, and occupational health disparities. American Journal of Industrial Medicine, 57, 495-515.

Layne, D. M., Rogers, B., \& Randolph, S. A. (2009). Health and gender comparisons in the long-haul trucking industry. $A A O H N$ Journal, 57, 405-413. doi:10.3928/08910162-20090916-01

Lemke, M., \& Apostolopoulos, Y. (2015). Health and wellness programs for commercial motor-vehicle drivers: Organizational assessment and new research directions. Workplace Health \& Safety, 63, 71-80. doi:10.1177/2165079915569740

Lemke, M. K., \& Apostolopoulos, Y. (2016). Policy, work organization and sleep health and safety of commercial drivers: Introducing a complex systems paradigm. Journal of Ergonomics, 6, 152-156. Retrieved from https://www.omicsonline.org /open-access/policy-work-organization-and-sleep-health-and -safety-of-commercialdrivers-introducing-a-complex-systems -paradigm-2165-7556-1000152.php?aid=67587

Lemke, M. K., Apostolopoulos, Y., Hege, A., Sönmez, S., \& Wideman, L. (2016). Understanding the role of sleep quality and sleep duration in commercial driving safety. Accident Analysis \& Prevention, 97, 79-86. doi:10.1016/j.aap.2016.08.024

Lemke, M. K., Apostolopoulos, Y., Hege, A., Wideman, L., \& Sönmez, S. (2017a). Work organization, sleep, and metabolic syndrome among long-haul truck drivers. Occupational Medicine, 67, 274-281. doi:10.1093/occmed/kqx029

Lemke, M. K., Apostolopoulos, Y., Hege, A., Wideman, L., \& Sönmez, S. (2017b). Work, sleep, and cholesterol levels of
U.S. long-haul truck drivers. Industrial Health, 55, 149-161. doi:10.2486/indhealth.2016-0127

Lemke, M. K., Hege, A., Apostolopoulos, Y., Wideman, L., \& Sönmez, S. (2017). Work and sleep among transport operators: Disparities and implications for safety. Journal of Transport \& Health, 7, 298-309.

Lemke, M. K., Hege, A., Perko, M., Sönmez, S., \& Apostolopoulos, Y. (2015). Work patterns, sleeping hours and excess weight in commercial drivers. Occupational Medicine, 65, 725-731. doi:10.1093/occmed/kqv080

Lemke, M. K., Meissen, G. J., \& Apostolopoulos, Y. (2016). Overcoming barriers in unhealthy settings: A phenomenological study of healthy truck drivers. Global Qualitative Nursing Research, 3, 1-9. doi:10.1177/2333393616637023

Litwiller, B., Snyder, L. A., Taylor, W. D., \& Steele, L. M. (2017). The relationship between sleep and work: A meta-analysis. Journal of Applied Psychology, 102, 682-699. doi:10.1037/ ap10000169

Lowden, A., Moreno, C., Holmback, U., \& Tucker, P. (2010). Eating and shift work: Effects on habits, metabolism, and performance. Scandanavian Journal of Work Environment \& Health, 36, 150-162.

Luckhaupt, S., Cohen, M., Li, J., \& Calvert, G. (2014). Prevalence of obesity among U.S. workers and associations with occupational factors. American Journal of Preventive Medicine, 46, 237-248.

McCallum, M., Sandquist, T., Mitler, M., \& Krueger, G. P. (2003). Commercial transportation operator fatigue management reference. Washington, DC: Department of Transportation Research and Special Programs Administration.

National Sleep Foundation. (n.d.). How much sleep do we really need? Retrieved from https://sleepfoundation.org/how-sleep -works/how-much-sleep-do-we-really-need/page/0/2

Newnam, S., Goode, N., Salmon, P., \& Stevenson, M. (2017). Reforming the road freight transportation system using systems thinking: An investigation of Coronial inquests in Australia. Accident Analysis \& Prevention, 101, 28-36. doi:10.1016/j. aap.2017.01.016

Ng, M. K., Yousuf, B., Bigelow, P. L., \& Van Eerd, D. (2015). Effectiveness of health promotion programmes for truck drivers: A systematic review. Health Education Journal, 74, 270-286.

Olson, R., Anger, W. K., Elliot, D. L., Wipfli, B., \& Gray, M. (2009). A new health promotion model for lone workers: Results of the Safety \& Health Involvement for Truckers (SHIFT) pilot study. Journal of Occupational and Environmental Medicine, 51, 1233-1246. doi:10.1097/JOM.0b013e3181c1dc7a

Oshio, T., Tsutsumi, A., \& Inoue, A. (2016). The association between job stress and leisure-time physical inactivity adjusted for individual attributes: Evidence from a Japanese occupational cohort survey. Scandinavian Journal of Work Environment \& Health, 42, 228-236.

Salmon, P. M., McClure, R., \& Stanton, N. A. (2012). Road transport in drift? Applying contemporary systems thinking to road safety. Safety Science, 50, 1829-1838.

Schnall, P., Dobson, M., \& Landsbergis, P. (2016). Globalization, work, and cardiovascular disease. International Journal of Health Services, 46, 656-692.

Shattell, M., Apostolopoulos, Y., Collins, C., Sönmez, S., \& Fehrenbacher, C. (2012). Trucking organization and men- 
tal health disorders of truck drivers. Issues in Mental Health Nursing, 33, 436-444.

Shattell, M., Apostolopoulos, Y., Sönmez, S., \& Griffin, M. (2010). Occupational stressors and the mental health of truckers. Issues in Mental Health Nursing, 31, 561-568. doi:10.3109/0161284 0.2010 .488783

Sieber, W. K., Robinson, C. F., Birdsey, J., Chen, G. X., Hitchcock, E. M., Lincoln, J. E., . . Sweeney, M. H. (2014). Obesity and other risk factors: The National Survey of US Long-Haul Truck Driver Health and Injury. American Journal of Industrial Medicine, 57, 615-626.

Sterman, J. D. (2000). Business dynamics: Systems thinking and modeling for a complex world. Boston, MA: Irwin/McGraw-Hill.

Taylor, A. H., \& Dorn, L. (2006). Stress, fatigue, health, and risk of road traffic accidents among professional drivers: The contribution of physical inactivity. Annual Review of Public Health, 27, 371-391. doi:10.1146/annurev.publhealth.27.021405.102117

Thompson, J., \& Stevenson, M. (2014). Associations between heavy-vehicle driver compensation methods, fatigue-related driving behavior, and sleepiness. Traffic Injury Prevention, 15(Suppl. 1), S10-S14.
Turner, L. M., \& Reed, D. B. (2011). Exercise among commercial truck drivers. AAOHN Journal, 59, 429-436.

U.S. Department of Transportation. (n.d.). Summary of hours-ofservice (HOS) regulations. Retrieved from https://www.fmcsa .dot.gov/sites/fmcsa.dot.gov/files/docs/HOS_Visor_Card_Oct 2013_508CLN.pdf

Virtanen, M., Jokela, M., Nyberg, S., Madsen, I., Lalluka, T., Ahola, K., . . . Burr, H. (2015). Long working hours and alcohol use: Systematic review and meta-analysis of published studies and unpublished individual participant data. British Medical Journal, 350, g7772. doi:10.1136/bmj.g7772

Wawzonek, P. A. (2016). In danger? An exploration of Canadian truck drivers' health through the Canadian Community Health Survey. Retrieved from https://uwspace.uwaterloo.ca /bitstream/handle/10012/10098/Wawzonek_Peter.pdf

Wenger, J. (2008). Freedom isn't free: Voices from the truck driving industry. New Solutions, 18, 481-491.

Yong, L., Li, J., \& Calvert, G. (2017). Sleep-related problems in the US working population: Prevalence and association with shiftwork status. Occupational and Environmental Medicine, 74, 93-104. 